\title{
Envisioning a Quantitative Studies Center: A Liberal Arts Perspective
}

\section{Gizem Karaali}

Department of Mathematics, Pomona College, Claremont, CA, gizem.karaali@pomona.edu

Philip I. Choi

Department of Physics and Astronomy, Pomona College, Claremont, CA

Sara Owsley Sood

Department of Computer Science, Pomona College, Claremont, CA

Eric B. Grosfils

Department of Geology, Pomona College, Claremont, CA

Follow this and additional works at: https://digitalcommons.usf.edu/numeracy

Part of the Mathematics Commons, and the Science and Mathematics Education Commons

\section{Recommended Citation}

Karaali, Gizem, Philip I. Choi, Sara Owsley Sood, and Eric B. Grosfils. "Envisioning a Quantitative Studies Center: A Liberal Arts Perspective." Numeracy 3, Iss. 1 (2010): Article 4. DOI: http://dx.doi.org/10.5038/ 1936-4660.3.1.4 


\title{
Envisioning a Quantitative Studies Center: A Liberal Arts Perspective
}

\begin{abstract}
Several academic institutions are searching for ways to help students develop their quantitative reasoning abilities and become more adept at higher-level tasks that involve quantitative skills. In this note we study the particular way Pomona College has framed this issue within its own context and what it plans to do about it. To this end we describe our efforts as members of a campus-wide committee that was assigned the duty of investigating the feasibility of founding a quantitative studies center on our campus. These efforts involved analysis of data collected through a faculty questionnaire, discipline-specific input obtained from each departmental representative, and a survey of what some of our peer institutions are doing to tackle these issues. In our studies, we identified three critical needs where quantitative support would be most useful in our case: tutoring and mentoring for entry-level courses; support for various specialized and analytic software tools for upper-level courses; and a uniform basic training for student tutors and mentors. We surmise that our challenges can be mitigated effectively via the formation of a well-focused and -planned quantitative studies center. We believe our process, findings and final proposal will be helpful to others who are looking to resolve similar issues on their own campuses.
\end{abstract}

\section{Keywords}

quantitative studies center, liberal arts, quantitative skills, academic support, peer mentoring, tutoring

Creative Commons License

(c) (1) (9)

This work is licensed under a Creative Commons Attribution-Noncommercial 4.0 License 


\section{Introduction}

During the 2008-2009 academic year, an ad hoc faculty committee was formed to investigate the feasibility of establishing a quantitative studies center (QSC) at Pomona College. In addition to the authors of this paper, the committee had representatives from across the formal, natural and social sciences. We collected information about the needs of each department, as well as the relevant current practices both on our campus and at other peer institutions. The end result of our efforts, a comprehensive report that summarized our findings, was presented to the Pomona College administration and faculty in May 2009.

Our process, findings and final proposal may be of interest to other academics at colleges similar to ours. In particular, our work could be relevant to others who may be reevaluating their own quantitative studies support systems or considering the development of their own QSC. This note is written with the hope of engaging a broad audience in a conversation about best practices in quantitative literacy/quantitative reasoning/quantitative skills/quantitative thinking (QL/QR/ QS/QT), which we anticipate will continue over the coming years as we move ahead with plans for our center.

Numeracy, since its inception, has consistently provided a platform for the discussion on QL/QR/QS/QT. In particular, it has recently published several articles detailing case studies of colleges across the nation that are developing QL/ QR/QT programs to address the respective needs of their faculty and student bodies. Recently published case studies have investigated changes to the curriculum or graduation requirements (Bressoud 2009, Steele et al. 2008), new course modules (Grawe et al. 2009), and faculty awareness workshops (Grawe et al. 2009, Steele et al. 2008).

Our context can be summarized as follows: many of our colleagues across the disciplines here at Pomona College see the need for particular types of quantitative skills support for their students. Our approach seeks to formulate an institutional solution to this problem in the form of a central support system capable of enhancing the efficiency with which we strive to deliver such aid. In particular, we focus our efforts on consolidating and strengthening the preexisting quantitative support offerings within our campus community.

As we describe our experiences formulating a vision for a future QSC, we include information we gathered about some peer institutions. Furthermore, we discuss what each department on campus desires out of such a center. Our focus on both the discipline-specific and the discipline-independent allows us to prescribe some quite concrete (albeit partial) solutions to what are arguably typical problems throughout the geography of American higher education. Thus, 
we hope to contribute to the discussion concerning how to "promote education that integrates quantitative skills across all disciplines and at all levels."

Our plans are admittedly modest in scope when compared to what has been going on at some other campuses across the nation. However, we expect that our center, once formed, will enable us to focus our attention on quantitative reasoning as a campus-wide issue. For instance, our Writing $\mathrm{Center}^{2}$ has been successful at encouraging many faculty members to incorporate a writing component into their courses; we envision that the future Quantitative Studies Center will play a similar role with respect to quantitative literacy. ${ }^{3}$

As noted above, we have not yet founded our center; we are indeed at the early planning stages. The nature of this article, therefore, is still provisional and necessarily theoretical. We understand, as a colleague warned us, that flexibility will be key as we go ahead and implement our design, since many new ideas and issues will undeniably come up in the actual realization stage (Mac an Bhaird 2009). We encourage our readers to contact us with comments and suggestions.

This note is organized as follows: In Section 2 we describe our context, our institution and its basic student makeup. Section 3 is an exposé of the problem our committee was assigned to study. There we identify, via the use of a faculty survey and direct input from individual departmental representatives, three critical areas where quantitative support would be most useful to our students: tutoring and mentoring for entry-level courses, support for various specialized and analytic software tools for upper-level courses, and a uniform basic training for student tutors and mentors. In Section 4 we present a comparative study of how some of our peer institutions are tackling similar problems. Section 5 describes our proposal and explains our vision for the future QSC. The terminal Section 6 concludes this note with a discussion of directions for further investigation.

\section{Background: Our Institution}

Pomona College is a highly selective liberal arts college located in Claremont, California, in the eastern-most tip of Los Angeles County. It is the founding member of the Claremont Colleges, ${ }^{4}$ a consortium of five liberal arts colleges (Pomona College, Claremont McKenna College, Harvey Mudd College, Pitzer

\footnotetext{
${ }^{1}$ A direct quote from the Numeracy front page [http://services.bepress.com/numeracy (accessed Sept. 4, 2009)].

${ }^{2}$ http://www.writing.pomona.edu/writingcenter/ (accessed Dec. 2, 2009).

3 The role of quantitative centers in supporting faculty and students has been the topic of a recent panel discussion ("The Role of Quantitative Literacy Centers in Supporting Students and Faculty," MathFEST 2008) organized by Maura Mast and Cinnamon Hillyard. A slideshow can be found at http://pc88092.math.cwu.edu/ montgomery/sigmaaql/_meetings/2008mf/MF-2008.pdf (accessed Nov. 17, 2009).

${ }^{4}$ Locally referred to as "the 5 -C."
} 
College and Scripps College) and two graduate institutions (Claremont Graduate University (CGU) and Keck Graduate Institute). The five undergraduate colleges and CGU are geographically contiguous; this allows students from each institution considerable access to the resources of the others. Overall, the Colleges serve more than 6000 students and offer almost 2500 courses each year. Each college offers majors and minors in most of the traditional disciplines.

Among its sister institutions in Claremont, Pomona is the largest both in size and traditional breadth of study. It enrolls approximately 1500 students and offers a diverse selection of courses among 45 different majors. Pomona maintains a low student-to-faculty ratio of 8:1 with 178 full-time instructional faculty members. Due to its size and breadth, Pomona attracts students from all five colleges, with as much as $10 \%$ of the Pomona course enrollment coming from its neighbors.

Students at the Claremont Colleges can generally be characterized as academic overachievers with average SAT scores ranking in the top 5 percentile nationwide. ${ }^{5}$ At Pomona specifically, scores are typically over 700 in each of the three areas (the median scores for the class entering in Fall 2008 were 740 in critical reading, 750 in math, and 730 in writing. $)^{6}$ In addition to strong standardized test scores, a large fraction of our students come in with better than average mathematics preparation, many of them having taken AP Calculus in high school. For instance, 56\% of the incoming class in Fall 2009 submitted at least one AP calculus score to the Pomona College registrar.

Upon arrival, many Pomona students take multiple courses in mathematics and progress beyond the introductory levels. For example, approximately $30 \%$ of all students take linear algebra (a course with a two-semester calculus prerequisite) ${ }^{7}$ and about half of our students takes statistics, either from the mathematics department or from one of the several other departments that offer courses in statistics as applied to their disciplinary fields. Furthermore, the sciences - formal, natural and social-are well represented within the College, accounting for as much as $80 \%$ of all degrees granted over the past decade.

The Pomona curriculum is quite flexible, allowing students to take courses from a wide variety of fields and still be able to lead a focused study of their major discipline. There is not a fixed general education core curriculum; instead, students are exposed to diverse fields of study as they fulfill their breadth requirements. These breadth requirements are organized around five areas:

\footnotetext{
${ }_{6}^{5}$ Based on 2008 data from http://www.collegeboard.com/ (accessed Aug. 10, 2009).

6 http://www.pomona.edu/Welcome/AboutPomona/FactsAndFigures.shtml (accessed Sept. 4, 2009)

${ }^{7}$ Despite these encouraging data, experience reveals that formal mathematics training does not translate into applied quantitative reasoning skills. Instructors in allied disciplines often find themselves going through several simpler problems before the students figure out how to use their mathematical training in specific contexts.
} 
Creative Expression; Social Institutions and Human Behavior; History, Values, Ethics and Cultural Studies; Physical and Biological Sciences; and Mathematical Reasoning. Students are required to take at least one course from each of these five areas. They can satisfy the mathematical reasoning area requirement (Area 5) by taking a course in mathematics (except pre-calculus), computer science, formal logic or statistics. Several courses in Area 2 and 4 also have substantial quantitative components.

Currently, there is not a campus-wide initiative to focus on $\mathrm{QR}$ across the curriculum or introduce new graduation requirements. For many years now, the general tendency among Pomona College faculty has been to decrease campuswide requirements as opposed to increasing them.

\section{Identifying Needs}

There are currently three primary avenues outside of the classroom through which students can enhance their analytical or quantitative reasoning skills at Pomona College. The first is through student- or faculty-led group mentor sessions organized on a weekly and/or as-needed basis by individual faculty members. The second is through one-on-one sessions with faculty members during office hours or by appointment. The last is via peer tutoring, which can be arranged through the Pomona College Student Affairs Office or the Claremont University Consortium's Office of Black Student Affairs.

Though there are many different ways that students can seek academic support for courses with quantitative components, there is unfortunately no centralized support system to coordinate these efforts. This is in contrast with the support systems in place for writing-related issues. Our Writing Center has been very well integrated with the rest of the academic structure, and the relevant support services are centralized and organized in a most effective manner. ${ }^{8}$

\section{Methods and Initial Findings}

Motivated by a sense that there are problems with our current quantitative tutoring and mentoring system, we decided to explore these issues further on our campus. In our investigations we used an anonymous faculty survey and reports from individual departmental representatives. We also incorporated an earlier internal report into our study.

\footnotetext{
${ }^{8}$ In order to make use of lessons learned from our Writing Center and to facilitate possible future cooperation with it, our committee welcomed the Writing Center director into our discussions, and benefited significantly from her participation. Although our current plans have not clarified how exactly to encourage the collaboration between the two centers, we are certain that such collaboration will be a crucial component of the final setup implemented.
} 
Early Findings. Many of the shortcomings we found in the current system, along with the proposed remedy of a student learning center, were well documented in a report produced by a 2005 Pomona College Teaching and Learning Center (TLC) Task Force. This Task Force identified two major sources of tutoring on campus: several individual departments keep lists of students who are willing to tutor their peers, and the Office of the Dean of Students has a running list of student tutors for a variety of courses at different levels. The two lists overlap but neither is complete. The Task Force recognized and explicitly pointed out the need for a centralized system to coordinate these efforts. The current system requires too much effort by a student seeking a tutor, often requiring multiple phone calls to set up an appointment, and does not offer a means of providing uniform tutor training. The Task Force also emphasized the importance of a centralized system by stating that its recommendation would be to "augment support for students in the sciences and economics; students who do not succeed in the gateway courses in these disciplines are often shut out from following their ambitions." Following this analysis of the problem, the Task Force recommended that the college hire a tutoring director and administrative assistant; these individuals would take on the role of hiring and training tutors, as well as managing a signup Web site, scheduling mentor sessions and coordinating with departments, among many other tasks.

Since the 2005 TLC report, the tutoring program organized through the Student Affairs Office has made significant strides, with program information and both tutor and tutee sign-up now available on-line. The streamlined process and improved awareness amongst first-year students has resulted in an increased demand. During the 2007/2008 academic year, roughly 75 students were tutored in approximately 100 classes. These numbers have the potential to increase since online requests have only recently been implemented and the dean's office is currently seeing greater demand than they can meet with available tutors. Also, despite the successful streamlining of the matching process, the issues with tutor training, scheduling study sessions, and student follow-up that were pointed out in the 2005 report remain largely unresolved.

Faculty Survey. To further understand how mentors and tutors are used at Pomona and to assess the overall demand for such services, we surveyed Pomona College faculty in the formal, natural and social sciences. (See Appendix A for more information on the survey). Through the faculty responses, we discovered that most tutoring and mentoring happens on campus during the evening and within departmental spaces. Course mentors are generally well utilized, though half of the respondents indicated that there are still some unmet tutoring or mentoring needs in their department. Common needs include private tutors for individuals who are struggling in a class and guidance on statistical analysis for seniors working on their senior theses. The responses also indicated that despite 
the large learning curve for most people in their first teaching roles, there is little formal training of mentors. This is likely because it is difficult for professors to find the time and resources needed to instruct mentors individually on sound teaching practices.

Departmental Needs. Our committee had representatives from most of the departments with quantitative needs. In particular, the departments represented were: biology, chemistry, computer science, economics, geology, mathematics, physics \& astronomy, and sociology. The departments of linguistics \& cognitive science, psychology and the programs in environmental analysis and neuroscience chose not to be represented on the committee. Thus we believe that we had input from the departments that most found the issue important and urgent.

To get more detailed information about the discipline-specific needs within our community, we asked all committee members to consult with their department. Below we summarize the outcome of the subsequent discussions.

- Biology, chemistry, computer science, economics, mathematics, and physics \& astronomy departments are interested in mentor sessions for introductory courses. The last four of these departments already have mentor programs for these courses in place, and approach the possible creation of a QSC with enthusiasm, though in some cases this enthusiasm is accompanied by some concern about how these respective departmental programs will be affected.

- Economics and mathematics departments also use mentor sessions for some advanced courses. More generally, most of the departments involved desire more extensive support for their advanced students. In particular, students majoring in biology, computer science, economics, geology and sociology could benefit from statistical support during their thesis work, while physics \& astronomy students require some assistance with a variety of software packages. Courses that include substantial quantitative components are also a regular part of the sociology major, and statistical support for these students is also on the wish list of the sociology faculty.

- Students in introductory computer science, economics, mathematics, and physics \& astronomy courses would benefit from a more efficient tutoring program.

\section{Results of our Inquiry}

A snapshot of the various ongoing efforts at the institutional, departmental, faculty and student level revealed many positives. Nonetheless, the committee identified some key gaps within our current support strategies: 
- Tutors (and mentors) are sometimes difficult to find for key classes and at times are not familiar with the material they are expected to teach.

- Quick or drop-in tutoring is difficult to arrange.

- No formal mechanism exists to facilitate knowledge transfer and best practices to mentors or across generations of mentors. There is a clear need for a system that eliminates redundancy in topical coverage, and also for a mechanism that can keep track of, compile, and disseminate the teaching techniques that work best.

- The current system of scheduling individual mentors for each class is often inefficient.

- Students often need assistance with computer statistical packages and similar software. Faculty members currently help out, teaching the use of such packages, but their time would in many cases be better spent on alternative instructional tasks.

The specific areas that we chose to focus on are: (1) coordination of courselevel mentoring efforts and individual tutoring services; (2) training for both mentors and tutors; and (3) support for advanced students wanting to develop their analytic or technical skills. We elaborate:

Entry-level Students: Group Mentoring and Individual Tutoring._Several departments organize mentor sessions for their introductory courses. Typically, these sessions are led by an advanced student (the mentor) who holds semiregular group meetings to answer course-related questions. Unfortunately, mentors often have limited training in anything but the course material and their pedagogical skills and resourcefulness can vary widely. Furthermore, the accuracy of content delivery is likely to vary from person to person and topic to topic (a factor that is difficult to evaluate without strict and persistent oversight).

It is worth noting that the 2005 TLC report focused on the role of tutors without differentiating between one-on-one and small group tutoring. This distinction is subtle but important. It is a well-established practice for departments to hire student mentors who offer regularly scheduled help sessions associated with particular classes. Depending on several factors, these help sessions can turn into group review sessions, which are efficient for reaching many students with the broadest needs but are ineffective for supporting students with outlying concerns. In those cases, individual attention is more appropriate.

Related to the issue of group vs. individual tutoring, there is some concern among faculty that the growing demand for tutors can only be met at the expense of a student-mentor pool that is already fairly limited in many departments. This was recognized in the 2005 report, namely that "we simply may have maximized 
the number of work study students available. There is not only inadequate training of tutors ... but there may also not be enough to go around." If insufficient tutor availability is indeed a limiting factor, then finding a way to make more efficient use of this resource would be advisable.

Upper-level Students: Advanced quantitative tools. Students at Pomona College are required to conclude their studies with the completion of a senior exercise. In several majors this takes the form of a senior thesis. Many times these theses involve mathematical or statistical tools and software packages that may not have been a central part of a student's earlier experience. Faculty therefore often find themselves helping a student deal with various technical support is sues instead of the main substance of the thesis.

A clear message from the faculty is that our intermediate- and upper-level students would benefit from support with advanced mathematical, statistical or data analysis tools. Unlike students in gateway courses, advanced students generally have few options beyond faculty. In a university setting, some of this technical support is often supplied by graduate students and post-docs who tend to be both more up-to-date with the latest software and analysis packages and less overwhelmed with administrative and related concerns; this type of resource is clearly lacking at most undergraduate colleges like ours.

Mentor and Tutor Training. As the faculty survey has shown, mentor sessions across the campus vary greatly in their quality and effectiveness. This variation is partially due to the fact that most mentors do not go through a formal vetting process before they start mentoring, and most receive little to no training before or during their mentoring activities. Some mentors are only marginally more knowledgeable than the students they are meant to mentor, and others simply lack interest in doing a good job. Then there are mentors, with an excellent grasp of the relevant material and a substantial amount of enthusiasm for the job, who do not have a good sense of how to help students with different needs. In most cases oversight is provided by the instructor teaching the particular course with which a mentor's sessions are associated, but such oversight is not uniform.

Faculty members are contacted for recommendations when a student applies to the campus student affairs office to be added to the current tutor list. Once again, after this point, there is not much quality control of the effectiveness of any given tutor. Tutors also do not go through training for the job.

Our discussions of the above points led our committee to decide that uniform basic training of mentors and tutors is desirable. Furthermore, we agreed that collecting together some tips and techniques that our students can learn in these training sessions and use in their teaching, whether in the form of group mentoring or peer tutoring, would be a good idea. A student version of a typical 
Teaching and Learning Library could further promote our efforts to make our student instructors more effective and successful.

Another theme that came up in our discussions was the need to ensure that the available quantitative support services reach all students who need them. There is often an unfortunate perception that academic support services such as tutoring and study centers are mainly for underperforming students. This perception is both inaccurate and detrimental. Students who carry this viewpoint are less likely to use the available resources, regardless of where they fall on the performance scale. Furthermore, faculty who share this perspective are less likely to support and encourage the use of these services. Therefore, we decided that one of our primary goals should be to develop a mechanism that can provide services to help all students by creating a campus atmosphere where getting support is seen as a natural part of learning. This is not an unrealistic goal, as our very own Writing Center on campus has dealt with this issue in its own context rather successfully.

Clearly none of these issues we discuss above are unique to Pomona College. It is indeed reasonable to expect that other institutions have identified similar problems and have looked to resolve them. Thus we decided to examine the QL/QR/QS/QT support infrastructures at several peer institutions

\section{Quantitative Studies Centers at Peer Institutions}

We conducted an informal survey of twelve liberal arts colleges: Amherst, Carleton, Claremont McKenna, Depauw, Harvey Mudd, Macalester, New College of Florida, Occidental, Smith, Swarthmore, Wellesley and Williams. ${ }^{9}$ Our main goal was to gather data about how these institutions tackle the fundamental issue of quantitative support. We focused on specifics such as kinds of quantitative support services provided, staffing, target audience, facilities, and how everything fits together within the broader academic support system infrastructure. We were able to obtain most of this information from the Web spaces of these institutions. In cases where we could locate the relevant contact information, we contacted program directors via email to get more detailed information. Appendix B provides a list and contact information for the institutions included in our survey.

In our investigations, we saw that most of these institutions have centralized their support services for quantitative studies. Four institutions (Amherst, New College, Smith, Williams) have a freestanding Quantitative Center, independent of their Writing Center and autonomous from the academic departments; five (Carleton, DePauw, Harvey Mudd, Macalaster, Occidental) have close

\footnotetext{
${ }^{9}$ These particular institutions were selected because of their many similarities to our own, in particular in size and student makeup. Basically we focused on those colleges that our fellow faculty committees and administration routinely make comparisons with.
} 
coordination and interdependence (to varying degrees) between their Quantitative and Writing Centers, in some cases offering both services through an "Academic Excellence" or "Academic Resource" facility. One institution (Wellesley) has an independent Quantitative Reasoning program as well as a stand-alone Teaching and Learning Center; the two cooperate in coordinating the QR support services. Two institutions (Claremont McKenna, Swarthmore) offer more amorphous support, through academic departments or a generalized tutoring service.

There are some strong commonalities. ${ }^{10}$ These commonalities suggest that just as some of the problems we are facing at Pomona are most likely not unique to our own campus, the possible solutions may also lie in concepts and constructs that are applicable across institutions.

More specifically, almost all of the institutions with Quantitative Centers or Academic Resource facilities that we have surveyed have a professional staff person who coordinates services and trains the student staff. In some cases (e.g., Wellesley) there are affiliated faculty liaisons or faculty directors involved as well. Within the Centers, most tutoring and review sessions are student led. The students are nominated, and in some cases selected, by faculty from the relevant departments. Most centers offer some combination of drop-in consultations, appointments, and group help sessions, and most provide detailed information about the schedule for course- or discipline-specific offerings on their Web sites. Most centers are staffed during normal business hours; however, student tutoring is frequently available in the evenings and over the weekends as well. Furthermore, with small touches like Williams' "if you bring a mug, you'll find we have something warm to drink and a cookie to go with it" approach, ${ }^{11}$ it is clear that each Center makes a serious effort to create a warm and welcoming environment for students.

In our efforts to overcome existing weaknesses in the quantitative support infrastructure on our campus, our committee had agreed to build on the common experiences and the combined wisdom of our peer institutions. Through our investigations we observed that many of these institutions have decided to build their solutions around some variation on the notion of a quantitative studies center. Thus we came to the conclusion that development of a similar centralized framework would potentially be beneficial in our own context as well and, more specifically, that such a development would hopefully eliminate many of the difficulties faced by our students and help address several issues we have been attempting to resolve.

\footnotetext{
${ }^{10}$ While we focus here on the commonalities, we should also note that there are some significant differences as well. For instance tutor training varies widely from one institution to another.

${ }^{11}$ A direct quote from http://www.williams.edu/resources/acad_resources/math_science/ (accessed September 6, 2009)
} 


\section{A Future QSC for Pomona College}

The final committee report presented to the Pomona faculty and administration in May 2009 outlined our committee's combined vision for establishing a Quantitative Studies Center (QSC) at Pomona College. Our narrative in this section follows, in broad strokes, the outline of this final report. In particular, in the following we focus consecutively on three main criteria: (1) the services the future QSC will provide; (2) the resources that we envision will be required for the effective operation of this new Center, including its staffing and space demands; and finally, (3) the main emphasis of this whole project - the students who will benefit from this new establishment.

\section{Services}

The primary objectives of the QSC will be to:

- administer a one-on-one tutoring $\operatorname{program}^{12}$ in coordination with the mentoring program; ${ }^{13}$

- provide both the infrastructure and training to support mentor sessions across multiple disciplines;

- offer workshops and support for various analytic software tools, with special focus on upper-level students;

- create a welcoming space that promotes collaborative and interdisciplinary study, thus encouraging students to seek and benefit from the available academic support services without the unproductive concern about the stigma of remedial help.

Functionally, the QSC will centralize some of the current mentoring and tutoring efforts, but in general it will enhance, rather than replace, the current offerings. For example, while the Student Affairs Office could continue to advise and identify students needing quantitative support, coordination of tutors and tutees would shift from multiple independent groups to the QSC. With respect to the mentor program, training and session coordination will be broadly offered;

\footnotetext{
12 The major national association that focuses on tutor and mentor training is College Reading and Learning Association (CRLA) which, among other things, offers tutor certifications and guidelines on tutor training. The Web site for CRLA is http://www.crla.net/ (accessed Dec. 2, 2009).

13 A possible model for mentor sessions we might consider is Supplemental Instruction (SI), a methodology that has been applied in many college campuses. Information on SI can be found at the Web site of the International Center for Supplemental Instruction at the University of Missouri- Kansas City: http://www.umkc.edu/cad/si/overview.shtml (accessed Dec. 2, 2009).
} 
however, individual faculty will decide if, when, and to what extent they wish to use QSC resources.

\section{Required Resources}

The QSC needs to be available for group mentor sessions, generally scheduled for the evenings, as well as one-on-one tutoring services, drop-in consultations and various training workshops throughout the day. The center should be aligned to the study hours of our students, i.e., minimally staffed in the morning and then more fully staffed in the afternoon and evening hours when tutor and mentor sessions are more likely to be in demand.

To achieve the goals outlined above, our QSC will require several positions. First, we will need a director, who will (1) exercise administrative oversight; (2) work closely with departments and programs to determine how best to support student learning; and (3) provide both initial and ongoing training/oversight for the student tutors and mentors in quantitative tutoring pedagogy. We suggest that the QSC Director be an administrative appointment with coterminous faculty status, so that the individual is well positioned to both instruct students and work with faculty across the relevant departments on curricular and pedagogical issues. Assigning faculty status to the position may also widen the applicant pool, positioning Pomona to attract the best possible candidate.

Second, the QSC will need an instructional specialist who will work closely with the faculty. This person will plan workshops, offer training and provide support for various statistical and analysis specialty software packages. This action will help our students acquire fundamental technical skills, and ensure that the latest techniques and software continue to be introduced to and utilized by our students effectively.

Third, the QSC will need an administrative support person, ideally full-time but at least half-time.

Finally the center will need to be staffed by a cadre of 5-C undergraduate and graduate student mentors throughout the day and evening. The mentors will hold scheduled mentor sessions throughout the week and will make themselves available before or after those sessions for both scheduled and drop-in tutoring sessions.

We envision a centrally located QSC with a mix of one-on-one tutoring offices, multiple group-study spaces, and some large multi-purpose common spaces. Though we are not at the stage of interior design, we believe that the space should be constructed to attract students and promote group study. Desirable features include large open areas with comfortable, modular furniture, numerous movable whiteboards and wireless connectivity. At this time we assume that the space needs and frequency of student usage will most likely be comparable to those of our Writing Center. Indeed, we are looking into 
possibilities for cooperation and collaboration between these two entities; a centrally located building housing both could be an appealing option.

\section{Students and the QSC}

The beneficiaries of the QSC will include students from a broad range of disciplines, classes, and quantitative skill levels. Following are four example students and how they would benefit from the QSC:

- Student A is a first-year introductory economics student. She has always been a strong math student who took Calculus $\mathrm{BC}^{14}$ calculus in high school but is not currently enrolled in math and is a bit rusty from the summer off. This student might drop into the QSC between afternoon classes for short refresher sessions when certain topics come up in her economics class, or drop into one of the Calculus II mentor sessions listed on the QSC schedule as she feels the need.

- Student B is a senior sociology major working on his thesis and wants to learn some advanced techniques using the STATA $^{15}$ statistical software package for his thesis. His advisor has gotten him started, but he'd rather spend their weekly thesis lunches discussing data plots, not constructing them. This student could drop into the biweekly STATA training seminars held at the QSC by the software specialist or one of the CGU graduate teaching fellows.

- Student $\mathrm{C}$ is struggling with his linear algebra class. He has been to the mentor sessions, but does not feel comfortable asking what he views as basic questions since many of the sessions tend to be dominated by the advanced students. He tried attending office hours, but his professor is so popular that lines go out the door and he cannot get the individual help he needs. He tried finding a tutor through the student affairs office, but the tutor he was matched with is not familiar with the particular approach used in the class he is taking. Through the QSC, this student could schedule tutoring sessions with a mentor who has committed to jointly tutoring and mentoring for this particular class.

- Student D is a senior mentor for an introductory physics class who holds two-hour sessions once a week. Her sessions are well utilized before exams and some of the assignment due dates, but attendance is inconsistent and some nights she sits alone in the classroom for the majority of the session. As a physics major and math minor, she is well prepared to tutor in a range of subjects from intermediate physics to

\footnotetext{
${ }^{14} \mathrm{http}: / /$ www.collegeboard.com/student/testing/ap/sub_calbc.html (accessed Dec. 2, 2009).

${ }^{15} \mathrm{http}: / / \mathrm{www}$. stata.com/ (accessed Dec. 2, 2009).
} 
introductory math and even some general chemistry (her first love). She regularly helps students in the dorm after her mentor sessions, but if she were to hold them at the QSC she could more easily make herself available during under-attended sessions. As with all tutors and mentors, her "areas of expertise" would be listed on her bio as well as the online QSC tutor schedule. ${ }^{16}$

\section{Conclusion}

After investigating the nature of the quantitative support shortcomings on our campus, and surveying comparable institutions to see how they meet similar needs, we recommended that our College pursue the establishment of a Quantitative Studies Center to help mitigate the challenges our students currently face. Effective design and ongoing development of such a center will be difficult, and clearly several different issues will need to be addressed in the future as we move forward with our plans. For instance, as we develop new support structures, we will need to ensure that we do not dismantle currently effective programs unless the new structures provide a sufficient or improved replacement. Moreover, we will need to figure out how to employ student workers efficiently across disciplines so that all areas are supported.

Assessment is another issue we need to investigate further. One common thread in the responses of several of the directors of the QSC's we contacted during our study was the lack of information on the effectiveness of the centers in question. ${ }^{17}$ The two most common reasons cited for this problem were that (1) the center is new or otherwise its development happened over a course of time, and so the "before and after" stages are hard to distinguish, and (2) students in general do not want to share the fact that they are getting help, so data are incomplete and hence difficult to interpret reliably.

Two methods that have traditionally been used in these contexts are anonymous student surveys and/or statistical analyses of student grades, as in Mac an Bhaird et al. (2009). More recently automatic programs that can track tutor use have become available. ${ }^{18}$ These new tools have the potential to help centers collect and analyze relevant data in order to measure their effectiveness as well as streamline some of the more routine organizational tasks.

\footnotetext{
${ }^{16}$ Note that Student D would not only be making better use of her time but also she would be benefiting from doing the extra tutoring. See for instance Falchikov (2001) or Ender and Newton (2000) for the many ways tutoring helps the tutors.

${ }^{17}$ We should nonetheless point out that there are some centers which have been successful at collecting and analyzing this kind of data (e.g., Wellesley).

18 Two such programs are TutorTrac [www.tutortrac.com (accessed Dec. 2, 2009)] and
} AccuTrack [www.accutrack.org (accessed Dec. 2, 2009)]. 
In the QL/QR/QS/QT literature assessment continues to be a topic of concern and research interest (Taylor 2009; Wallace et al. 2009). There is clearly an ongoing need to ask questions and try to formulate ways to find answers about the effectiveness of the instruction performed at QSC's nationwide. In that spirit, we expect this note will be the beginning of our part in a broader educational conversation that is likely to continue for the coming years as we move ahead with our plans.

\section{Acknowledgments}

We would like to thank several people who helped us during the course of the work that led to this note. In particular our thanks go to: Margaret Adorno, registrar at Pomona College, Jennifer Rachford, director of institutional research at Pomona College, Katharine Rosacker, Registrar's Office at Pomona College, the 2005 TLC Task Force who shared their earlier report with us, the rest of the 2008-2009 Quantitative Studies Center committee (Bowman Cutter, Laura Hoopes, Jill Grigsby, Malkiat Johal, Richard Lewis and Dara Regaignon), and last but not the least the many people who responded to our many questions about quantitative centers and programs in their respective institutions: Duff Cooper, David Ehren, Nathan Grawe, Jennifer Innes, Julieanne Lucking, Ciarán Mac an Bhaird, Russ Petricka, Roberta Schotka and Corrine Taylor. We also thank the referees and editor whose many comments and suggestions significantly improved our article.

\section{References}

Bressoud, David. 2009. Establishing the Quantitative Thinking Program at Macalester. Numeracy, 2(1): Article 3. http://dx.doi.org/10.5038/1936-4660.2.1.3 (accessed Dec. 2, 2009).

Ender, Steven C., and Fred B. Newton. 2000. Students helping students: A guide for peer educators on college campuses. San Francisco: Jossey Bass.

Falchikov, Nancy. 2001. Learning together: Peer tutoring in higher education. London-New York: RoutledgeFalmer.

Grawe, Nathan D. and Carol A. Rutz. 2009. Integration with writing programs: A strategy for quantitative reasoning program development. Numeracy, 2(2):

Article 2. http://dx.doi.org/10.5038/1936-4660.2.2.2 (accessed Dec 2, 2009). Mac an Bhaird, Ciarán. 2009. Personal correspondence.

Mac an Bhaird, Ciarán, Tadhg Morgan and Ann O'Shea. 2009. The impact of the mathematics support centre on the grades of first year students at the National University of Ireland Maynooth. Teaching Mathematics and Its Applications 28: 117-122. http://dx.doi.org/10.1093/teamat/hrp014 
Steele, Benjamin and Semra Kiliç-Bahi. 2008. Quantitative literacy across the curriculum: A case study. Numeracy, 1(2): Article 3. http://dx.doi.org/10.5038/1936-4660.1.2.3 (accessed May 29, 2009).

Taylor, Corrine H. 2009. Assessing quantitative reasoning. Numeracy, 2(2): Article 1. http://dx.doi.org/10.5038/1936-4660.2.2.1 accessed Dec. 2, 2009).

Wallace, Dorothy, Kim Rheinlander, Steven Woloshin, and Lisa Schwartz. 2009. Quantitative literacy assessments: An introduction to testing tests, Numeracy, 2(2): Article 3. http://dx.doi.org/10.5038/1936-4660.2.2.3 (accessed Dec. 2, 2009).

\section{Appendix A: Faculty Survey Questions}

Here we list the questions asked to Pomona College faculty in the formal, natural and social sciences through an anonymous survey, administered via Survey Monkey. ${ }^{19}$ In the questions that follow, we use the term "mentor" to refer to a hired course assistant who works directly with students outside of class or lab time. The questions were aimed to aggregate numerical data; however, questions 1-4, 6-7 allowed for free-form responses via a text box.

1. On average, how many mentor hours do you schedule per week?

2. How well do students utilize these mentors?

3. How much (if any) training do the mentors currently receive? Is there any type of training that you think might be valuable?

4. Where do the mentors meet with students?

5. What time of day are these sessions held?

6. Are there other mentoring or tutoring needs in your department that are currently not being met?

7. On average, how many hours per week do you spend meeting with students outside of class; helping them with an assignment or some other task which could conceivably be fulfilled by a student tutor or mentor?

\footnotetext{
${ }^{19}$ http://www.surveymonkey.com (accessed Dec. 2, 2009).
} 


\section{Appendix B: Contact Data on Peer Institutions}

Below we present some of the basic contact data on the peer institutions discussed in this note. These were collected from the Web sites of the respective centers and are listed here for the reader's convenience.

Amherst College: The Moss Quantitative Center

URL: https://www.amherst.edu/academiclife/support/moss_quantitative_center

Contacts: Jennifer Innes, Director, and Timothy St.Onge, Mathematics Counselor

Carleton College: Mathematics Skills Center

URL: http://apps.carleton.edu/campus/asc/msc/

Contact: Russ Petricka

Claremont McKenna College: Resident Technology Assistants

URL: http://www.claremontmckenna.edu/its/StudentGuide/RTA/

Claremont McKenna College: The Writing Center

URL: http://www.claremontmckenna.edu/writing/

Contact: Justin Young, Director

Depauw University: Quantitative Reasoning Center

URL: https://apps.carleton.edu/campus/asc/msc/

Contact: Rich Martoglio

Harvey Mudd College: Department of Learning Programs

URL:

http://www.hmc.edu/academicsclinicresearch/academicresources/learningprogram

$\underline{\text { s.html }}$

Contact: Wendy Menefee-Libey

Macalester College: MAX Center: Macalester Academic Excellence Center

URL: www.macalester.edu/max/

Contacts: Julie Lucking, Department Coordinator, and Dave Ehren, Director and

Math Counselor

New College of Florida: Quantitative Resource Center

URL: http://www.ncf.edu/qrc

Contact: Duff Cooper 
Occidental College: Center for Academic Excellence

URL: http://departments.oxy.edu/cae/

Contact: Jerilynn Powers, Sr. Administrative Assistant

Smith College: Quantitative Learning Center

URL: http://www.smith.edu/qle/

Contact: Catherine McCune

Swarthmore College: Academic Advising Support Services

URL: http://www.swarthmore.edu/academicadvising.xml

Contact: Tracey Rush

Wellesley College: Quantitative Reasoning Program

URL: http://www.wellesley.edu/QR/

Contact: Corrine Taylor, Director

Wellesley College: Learning and Teaching Center

URL: http://www.wellesley.edu/PLTC/

Contacts: Roberta Schotka, Director of Programs, and Beth Hennessey, Faculty

Director

Williams College: Math and Science Resource Center

URL: http://www.williams.edu/resources/acad resources/math science/

Contact: Joyce P. Foster, Director of Academic Resources 